\title{
The Effect of Losartan and Amlodipine on Left Ventricular Diastolic Function and Atherosclerosis in Japanese Patients with Mild-to-Moderate Hypertension (J-ELAN) study
}

\author{
Kazuhiro Yamamoto ${ }^{1,2}$, Hitoshi Ozaki ${ }^{3}$, Ken Takayasu ${ }^{4}$, Noriyuki Akehi ${ }^{5}$, Sugao Fukui ${ }^{6}$, Akihiko Sakai ${ }^{7}$, \\ Mineo Kodama ${ }^{8}$, Tsuyoshi Shimonagata ${ }^{9}$, Keiji Kobayashi ${ }^{10}$, Mitsushige Ota ${ }^{11}$, Yasunori Horiguchi ${ }^{12}$, \\ Shoji Ebisuno ${ }^{13}$, Yoshiki Katsube ${ }^{14}$, Tsutomu Yamazaki ${ }^{15}$, Hiroshi Ohtsu ${ }^{16}$ and Masatsugu Hori ${ }^{1,17}$
}

This study was a prospective, randomized, open, blinded endpoint study to assess the effects of angiotensin II type 1 receptor blocker, losartan, compared with calcium channel blocker, amlodipine, on left ventricular (LV) diastolic function and atherosclerosis of the carotid artery in Japanese patients with mild-to-moderate hypertension, LV hypertrophy, diastolic dysfunction and preserved systolic function. Fifty-seven patients were randomly assigned to losartan- or amlodipine-based treatment groups and were followed up for 18 months. Blood pressure was similarly reduced by both regimens. Losartan shortened the transmitral E-wave deceleration time, and amlodipine reduced LV mass index; however, there was no significant difference in the percent changes of these indices between the two groups. Mean carotid intima-media thickness (mean IMT) as well as plaque score significantly increased in the amlodipine-based regimen (pre: $1.05 \pm 0.26 \mathrm{~mm}$, follow-up: $1.23 \pm 0.33 \mathrm{~mm}$, $P=0.0015$ ), but not in the losartan-based regimen (pre: $1.08 \pm 0.35 \mathrm{~mm}$, follow-up: $1.16 \pm 0.52 \mathrm{~mm}, P=$ non-significant). The percent increase in mean IMT in the amlodipine-based regimen tended to be large compared with the losartan-based regimen (amlodipine: $19.8 \pm 23.7 \%$, losartan: $6.9 \pm 23.3 \%, P=0.06$ ). Under similar reduction of blood pressure, losartan is likely effective in protecting the progression of atherosclerosis of the carotid artery compared with amlodipine. Losartan may improve LV diastolic function, and amlodipine may attenuate LV hypertrophy; however, this study cannot make consecutive remarks about the superiority of either treatment regimen in the effects on cardiac function and geometry. This study has been registered at http://www.umin.ac.jp/ctr/listj/ (identifier C000000319).

Hypertension Research (2011) 34, 325-330; doi:10.1038/hr.2010.237; published online 2 December 2010

Keywords: angiotensin receptor blocker; atherosclerosis; calcium channel blocker; diastolic dysfunction

\section{INTRODUCTION}

Hypertension is one of the major risk factors of cardiovascular structural and functional impairment. ${ }^{1}$ There have been many clinical trials to compare the effects of anti-hypertensive agents on cardiovascular function, geometry and events. However, most were conducted in the Caucasians, and the ethnic difference in the effects of pharmacological therapies is likely present, ${ }^{2,3}$ suggesting that the results of the studies in Western countries cannot be simply extrapolated to Japanese hypertensive patients.

Left ventricular (LV) diastolic dysfunction is a risk of cardiovascular events, ${ }^{4,5}$ and hypertension is considered as a principal cause for the progression of diastolic dysfunction in Japan, as well as Western countries. ${ }^{6}$ Carotid atherosclerosis, another risk of cardiovascular events, ${ }^{7,8}$ is associated with LV diastolic dysfunctions. ${ }^{9}$ Calcium channel blocker (CCB) and angiotensin II type 1 receptor blocker (ARB) are most widely used for the treatment of hypertension in Japan, and both are expected to improve diastolic function, independent of their depressor effects. Even without the reduction of blood pressure, CCB prevents the phenotype shift of collagen synthesis; ${ }^{10}$ ARB attenuates myocyte hypertrophy and functional alterations of calcium-handling proteins in myocyte, and prevents deposition of extracellular matrix, the phenotype shift of collagen synthesis and the cross-linked collagen accumulation. ${ }^{11,12}$

\footnotetext{
${ }^{1}$ Department of Cardiovascular Medicine, Osaka University Graduate School of Medicine, Suita, Japan; ${ }^{2}$ The Center for Advanced Medical Engineering and Informatics, Osaka University, Suita, Japan; ${ }^{3}$ Ozaki Clinic, Higashiosaka, Japan; ${ }^{4}$ Takayasu Clinic, Sakai, Japan; ${ }^{5}$ Settsuiseikai Hospital, Settsu, Japan; ${ }^{6}$ Kawasaki Hospital, Kaizuka, Japan; ${ }^{7}$ Sakai Clinic, Kadoma, Japan; ${ }^{8}$ Kodama Clinic, Nishinomiya, Japan; ${ }^{9}$ Shimonagata Clinic, Nishinomiya, Japan; ${ }^{10}$ Kobayashi Clinic, Sakai, Japan; ${ }^{11}$ Ohta Clinic, Minoo, Japan; ${ }^{12}$ Horiguchi Clinic, Ikeda, Japan; ${ }^{13}$ Ebisuno Clinic, Izumiotsu, Japan; ${ }^{14}$ Katsube Clinic, Nishinomiya, Japan; ${ }^{15}$ Department of Clinical Epidemiology \& Systems, The University of Tokyo, Tokyo, Japan and ${ }^{16}$ Department of Clinical Trial Data Management, The University of Tokyo, Tokyo, Japan

${ }^{17}$ Current address: Osaka Medical Center for Cancer and Cardiovascular Diseases, Osaka, Japan.

Correspondence: Dr K Yamamoto, Department of Cardiovascular Medicine, Osaka University Graduate School of Medicine, 2-2 Yamadaoka, Suita 565-0871, Japan.

E-mail: kazuhiro@medone.med.osaka-u.ac.jp
}

Received 18 May 2010; revised 12 July 2010; accepted 8 September 2010; published online 2 December 2010 
This study was designed to assess the effects of the ARB, losartan, compared with the CCB, amlodipine, on LV diastolic function and atherosclerosis of the carotid artery in Japanese patients with mildto-moderate hypertension, LV hypertrophy, diastolic dysfunction and preserved systolic function.

\section{METHODS}

The Effect of Losartan and Amlodipine on Left Ventricular Diastolic Function in Japanese Patients with Mild-to-Moderate Hypertension (J-ELAN) study was a prospective, randomized, open, blinded endpoint (PROBE) design, and the rationale and complete design of this study have been published elsewhere. ${ }^{13}$ The Ethical Committee in Osaka University Graduate School of Medicine approved this study on 27 December 2004 (No. 436), and this study was conducted in accordance with the principles stated in the Declaration of Helsinki. Written informed consent was given by all patients before entry into the study.

This study has been registered at http://www.umin.ac.jp/ctr/listj/ (identifier C000000319).

\section{Participants and treatment}

Briefly, hypertensive patients with LV hypertrophy and diastolic dysfunction who met the following entry criteria were enrolled: (1) age $\geqslant 20$ years old, (2) presence of mild-to-moderate hypertension (systolic blood pressure $\geqslant 140$ and $\leqslant 200 \mathrm{~mm} \mathrm{Hg}$, diastolic blood pressure $\geqslant 90$ and $\leqslant 110 \mathrm{~mm} \mathrm{Hg}$ ), (3) presence of LV hypertrophy (the ratio of LV mass to body surface area (LV mass index) $\geqslant 120 \mathrm{~g} \mathrm{~m}^{2}$ in men and $\geqslant 105 \mathrm{~g} \mathrm{~m}^{2}$ in women, ${ }^{14}$ or LV wall thickness $>11 \mathrm{~mm}^{15}$ ), (4) presence of $\mathrm{LV}$ diastolic dysfunction (the ratio of peak early to late diastolic filling velocities $(E / A)<1.0$ or $>1.5$, an E-wave deceleration time (DT) $<160 \mathrm{~ms}$ or $>280 \mathrm{~ms}$, isovolumic relaxation time (IRT) $<60 \mathrm{~ms}$ or $\left.>105 \mathrm{~ms}^{15}\right)$, (5) LV ejection fraction $\geqslant 50 \%$. Patients who had been treated with angiotensin-converting enzyme (ACE) inhibitor or ARB within 5 months before enrollment, or with $\beta$-blocker or CCB within 4 weeks were excluded. Finally, 57 patients were randomized to either losartan $50 \mathrm{mg}$ once daily or amlodipine $2.5 \mathrm{mg}$ once daily. After 4 weeks on the initial dose, patients were titrated up to losartan $100 \mathrm{mg}$ or amlodipine $5 \mathrm{mg}$ once daily, depending on blood pressure response. The target blood pressure was systolic blood pressure $<140 \mathrm{~mm} \mathrm{Hg}$ and diastolic blood pressure $<90 \mathrm{~mm} \mathrm{Hg}$. The third and fourth steps involved the addition of thiazide diuretics, $\alpha$-blockers or other medication, with the exception of ARB, CCB, ACE inhibitors or $\beta$-blockers.

\section{Data collection}

In both groups, conventional transthoracic echocardiography, ultrasonography of the left and right common carotid arteries, and blood assay were conducted before and 18 months after the randomization.

Transthoracic echocardiographic examinations were conducted to measure left atrial and LV cavity sizes and LV wall thickness, as previously described. ${ }^{16,17} \mathrm{EF}$ was calculated by a modification of the method of Quinones et al. ${ }^{18}$ and $\mathrm{LV}$ mass was calculated by the formula derived from the data of the American Society of Echocardiography, ${ }^{19}$ as previously described. ${ }^{16,17}$ The pulsed Doppler transmitral flow velocity curve was recorded to measure $E / A$, DT and IRT. ${ }^{20}$ Mean carotid intima-media thickness (mean IMT) and plaque score were calculated as previously described. ${ }^{21,22}$ These recordings and measurements were performed by sonographers from Advanced Harmonic Information Technology, Osaka, Japan, who were unaware of the study group assignment.

In addition to serum creatinine and uric acid, serum high-sensitive C-reactive protein (hs-CRP) was measured using nephelometric assay with commercially available kits (Dade Behring Marburg GmbH, Marburg, Germany). Plasma concentration of brain natriuretic peptide (BNP) was measured using chemiluminescent enzyme immunoassay with commercially available kits (Shionogi, Osaka, Japan). Plasma concentration of the amino-terminal propeptide of type III collagen was measured using immunoradiometric assay with commercially available kits (CIS Bio International, Bagnols/Ceze, France). Plasma carboxyterminal telopeptide of collagen type I was measured using radioimmunoassay with commercially available kits (Orion Diagnostica, Espoo, Finland). These measurements were performed by FALCO Biosystems, Kyoto, Japan.

\section{Statistical analysis}

Values are expressed as mean \pm s.d. All the analyses were performed according to the intention-to-treat principle using the SAS system. Baseline patient characteristics were compared using $\chi^{2}$ tests and unpaired Student's $t$-test. Intraindividual changes following the treatment in each group were assessed using Student's $t$-test for paired data. Changes in parameters were presented as the ratio of the changes to the baseline values, and their difference between the groups was assessed using unpaired Student's $t$-test. Results were considered significant at a probability value of less than 0.05 .

\section{RESULTS}

\section{Study profile and baseline characteristics}

Baseline patient characteristics are shown in Tables 1 and 2. There was no difference in age, sex ratio, blood pressure, comorbidity, echocardiographic indices, mean IMT, plaque score and data of blood test, except for left atrial dimension between the two groups. In the losartan-based treatment group $(n=29), 11$ patients were treated with $\alpha$-blockers before the initiation of losartan, and 5 of 11 patients stopped $\alpha$-blockers at the initiation. Ten patients were treated with thiazide diuretics before the initiation of losartan, and 5 of 10 patients stopped thiazide diuretics at the initiation. In the amlodipine-based treatment group $(n=28), 10$ patients were treated with $\alpha$-blockers before the initiation of amlodipine, and 6 of 10 patients stopped $\alpha$-blockers at the initiation. Twelve patients were treated with thiazide diuretics before the initiation of amlodipine, and 7 of 12 patients stopped thiazide diuretics at the initiation. There was no significant difference in the prescription ratio of additional anti-hypertensive drugs between the losartan- and amlodipine-based treatment groups.

Effects of treatment on blood pressure at follow-up for 18 months Of 29 patients in the losartan-based treatment group, 3 were lost to follow-up: death due to infection $(n=1)$ and withdrawal of informed consent $(n=2)$. In the amlodipine-based treatment group, 5 of 29 patients were lost to follow-up: sudden death $(n=1)$, withdrawal of informed consent $(n=1)$ and other $(n=3)$. There was no hospitalization because of cardiovascular or cerebrovascular events. Losartan was

Table 1 Baseline patient characteristics

\begin{tabular}{|c|c|c|c|}
\hline & Losartan & Amlodipine & P-value \\
\hline$n$ & 29 & 28 & \\
\hline Age (years) & $61 \pm 13$ & $61 \pm 9$ & 0.911 \\
\hline Sex (male:female) & $24: 5$ & $21: 7$ & 0.530 \\
\hline Systolic blood pressure $(\mathrm{mm} \mathrm{Hg})$ & $150 \pm 21$ & $157 \pm 18$ & 0.188 \\
\hline Diastolic blood pressure $(\mathrm{mm} \mathrm{Hg})$ & $91 \pm 12$ & $96 \pm 14$ & 0.151 \\
\hline Heart rate (b.p.m.) & $76 \pm 10$ & $75 \pm 13$ & 0.923 \\
\hline \multicolumn{4}{|l|}{ Comorbidity (\%) } \\
\hline Dyslipidemia & 62 & 57 & 0.790 \\
\hline Diabetes mellitus & 10 & 4 & 0.612 \\
\hline Coronary artery disease & 0 & 0 & - \\
\hline Cerebrovascular disease & 3 & 4 & $>0.999$ \\
\hline \multicolumn{4}{|l|}{ Medications (\%) } \\
\hline$\alpha$-Blockers & 38 & 36 & $>0.999$ \\
\hline Diuretics & 34 & 43 & 0.592 \\
\hline Statins & 10 & 11 & $>0.999$ \\
\hline Anti-platelet agents & 10 & 14 & 0.706 \\
\hline
\end{tabular}


Table 2 Baseline data

\begin{tabular}{|c|c|c|c|}
\hline & Losartan & Amlodipine & P-value \\
\hline \multicolumn{4}{|l|}{ Echocardiography } \\
\hline LV end-diastolic dimension (mm) & $46 \pm 6$ & $47 \pm 7$ & 0.420 \\
\hline Ejection fraction $(\%)$ & $71 \pm 6$ & $73 \pm 8$ & 0.378 \\
\hline LV mass index $\left(\mathrm{g} \mathrm{m}^{2}\right)$ & $131 \pm 33$ & $143 \pm 47$ & 0.296 \\
\hline Left atrial dimension ( $\mathrm{mm}$ ) & $36 \pm 8$ & $39 \pm 5$ & 0.04 \\
\hline$E / A$ & $0.86 \pm 0.28$ & $0.82 \pm 0.21$ & 0.452 \\
\hline DT (ms) & $237 \pm 63$ & $236 \pm 55$ & 0.979 \\
\hline IRT (ms) & $128 \pm 61$ & $114 \pm 29$ & 0.277 \\
\hline \multicolumn{4}{|l|}{ Carotid ultrasonography } \\
\hline Mean IMT (mm) & $1.08 \pm 0.34$ & $1.03 \pm 0.27$ & 0.572 \\
\hline Plaque score & $5.63 \pm 5.10$ & $5.59 \pm 5.30$ & 0.980 \\
\hline \multicolumn{4}{|l|}{ Blood sample } \\
\hline BNP $\left(\mathrm{pg} \mathrm{ml}^{-1}\right)$ & $96 \pm 169$ & $39 \pm 40$ & 0.107 \\
\hline PIIIP $\left(U \mathrm{ml}^{-1}\right)$ & $0.6 \pm 0.2$ & $0.6 \pm 0.3$ & 0.760 \\
\hline $\operatorname{CITP}\left(\mathrm{ng} \mathrm{ml}^{-1}\right)$ & $4.0 \pm 2.6$ & $3.3 \pm 1.1$ & 0.212 \\
\hline hs-CRP (ng ml-1) & $1004 \pm 1030$ & $2294 \pm 3835$ & 0.103 \\
\hline Creatinine $\left(\mathrm{mg} \mathrm{dl}^{-1}\right)$ & $0.9 \pm 0.2$ & $0.8 \pm 0.2$ & 0.06 \\
\hline Uric acid $\left(\mathrm{mg} \mathrm{dl}^{-1}\right)$ & $6.8 \pm 1.7$ & $7.1 \pm 1.6$ & 0.410 \\
\hline
\end{tabular}

Abbreviations: BNP, brain natriuretic peptide; CITP, carboxy-terminal telopeptide of collagen type I; DT, E-wave deceleration time; E/A, ratio of peak early to late diastolic filling velocities; hs-CRP, high-sensitive C-reactive protein; IMT, intima-media thickness; IRT, isovolumic hs-CRP, high-sensitive C-reactive protein; IMT, intima-media thickness; IRT, isovolumic
relaxation time; LV, left ventricular; PIIIP, aminoterminal propeptide of type III collagen.

not prescribed at follow-up in 3 of the 26 patients of the losartanbased treatment group, but the data of these patients were included in the analysis in compliance with the study design. Thus, the data of 26 patients of the losartan-based treatment group and of 23 patients of the amlodipine-based treatment group were analyzed. At 18 months after the initiation of the treatment regimens, the mean dose of losartan was $79 \mathrm{mg} \mathrm{day}^{-1}$, and that of amlodipine was $4.8 \mathrm{mg} \mathrm{day}^{-1}$. $\alpha$-Blockers were prescribed in nine patients of the losartan-based treatment group, and thiazide diuretics were prescribed in eight patients. In the amlodipine-based treatment group, $\alpha$-blockers were prescribed in 6 patients, and thiazide diuretics were prescribed in 10 patients. Anti-hypertensive medications other than $\alpha$-blockers and thiazide diuretics were prescribed in one patient of the amlodipinebased treatment group and in four patients of the losartan-based treatment group. There was no significant difference in the prescription ratio of additional anti-hypertensive drugs between the losartan- and amlodipine-based treatment groups.

Systolic and diastolic blood pressures were significantly lowered in both groups. Systolic/diastolic blood pressure after an 18-month treatment was $131 / 80 \mathrm{~mm} \mathrm{Hg}$ (s.d.: 12/10) for losartan-based regimen and 134/82 mm Hg (s.d.: 10/9) for amlodipine-based regimen. There was no significant difference between the groups. Heart rate did not change in either group.

\section{Effects of treatment on LV geometry, LV diastolic function and} atherosclerosis of the carotid artery

LV end-diastolic dimension (losartan: $45 \pm 6 \mathrm{~mm}$, amlodipine: $45 \pm$ $6 \mathrm{~mm}$ ), ejection fraction (losartan: $71 \pm 8 \%$, amlodipine: $72 \pm 9 \%$ ), left atrial dimension (losartan: $38 \pm 7 \mathrm{~mm}$, amlodipine: $38 \pm 5 \mathrm{~mm}$ ), E/A (losartan: $0.91 \pm 0.34$, amlodipine: $0.86 \pm 0.25$ ) and IRT (losartan: $117 \pm 34 \mathrm{~ms}$, amlodipine: $115 \pm 26 \mathrm{~ms}$ ) at follow-up were not significantly different from those before the initiation of the treatment regimen in either group. $E / A<1$ was met at the study enrollment by 23 of 26 patients of the losartan-based regimen and 22 of the 23

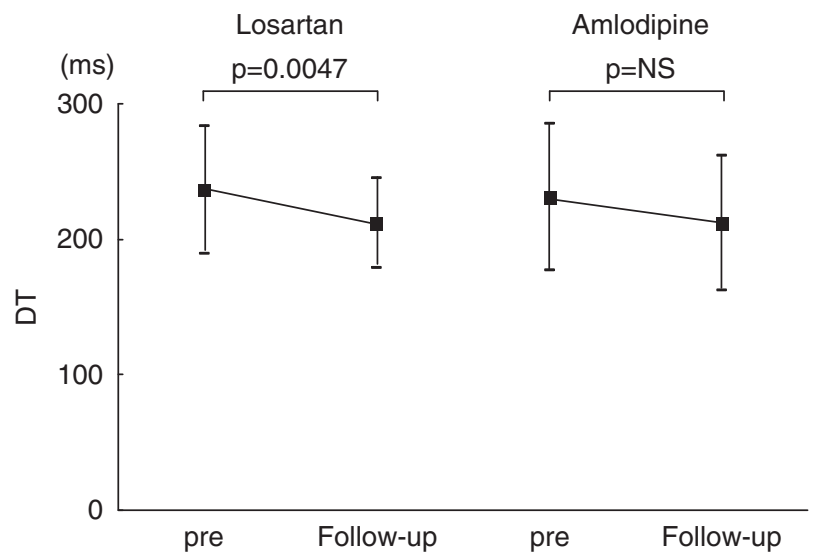

Figure 1 Changes in E-wave deceleration time (DT) in each treatment regimen.

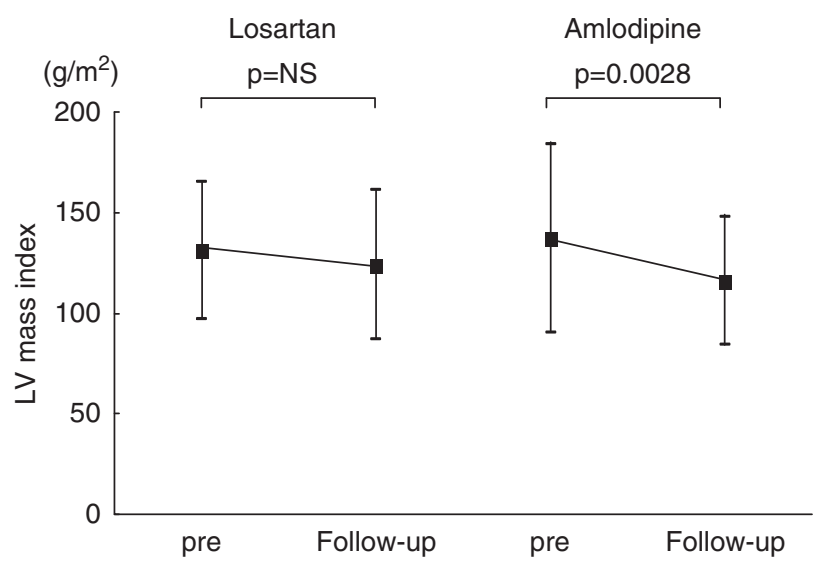

Figure 2 Changes in left ventricular (LV) mass index in each treatment regimen.

patients of the amlodipine-based regimen. Even in these selected patients with low E/A before treatment regimen, E/A was not significantly changed by either treatment.

DT was significantly shortened by the losartan-based regimen ( $212 \pm 33 \mathrm{~ms}$ at follow-up), but not by the amlodipine-based regimen ( $212 \pm 50 \mathrm{~ms}$ at follow-up) (Figure 1$)$. LV mass index was significantly reduced by the amlodipine-based regimen $\left(116 \pm 32 \mathrm{~g} \mathrm{~m}^{2}\right.$ at followup), but not by the losartan-based regimen $\left(124 \pm 37 \mathrm{~g} \mathrm{~m}^{2}\right.$ at follow-up) (Figure 2). However, the percent changes in DT or LV mass index were not significantly different between the regimens (DT: losartan $-8.4 \pm 13.7 \%$, amlodipine $-4.1 \pm 28.3 \%, P=0.51$; LV mass index: losartan $-4.4 \pm 13.7 \%$, amlodipine $-9.4 \pm 24.4 \%, P=0.39$ ).

The mean IMT or plaque score did not change in the losartan-based regimen (mean IMT: $1.16 \pm 0.52 \mathrm{~mm}$, plaque score: $7.20 \pm 7.59$, at follow-up), but significantly increased in the amlodipine-based regimen (mean IMT: $1.23 \pm 0.33 \mathrm{~mm}$, plaque score: $8.67 \pm 6.38$, at followup) (Figure 3). The percent increase in mean IMT tended to be small in the losartan-based regimen as compared with the amlodipine-based regimen (losartan: 6.9 $\pm 23.3 \%$, amlodipine: $19.8 \pm 23.7 \%, P=0.06$ ) As there were patients whose plaque score was 0 before the initiation of the treatment regimen, the percent change in plaque score could not be compared between the groups.

BNP (losartan: $69 \pm 128 \mathrm{pg} \mathrm{ml}^{-1}$, amlodipine: $31 \pm 47 \mathrm{pg} \mathrm{ml}^{-1}$ ), aminoterminal propeptide of type III collagen (losartan: $0.6 \pm 0.2 \mathrm{U} \mathrm{ml}^{-1}$, 

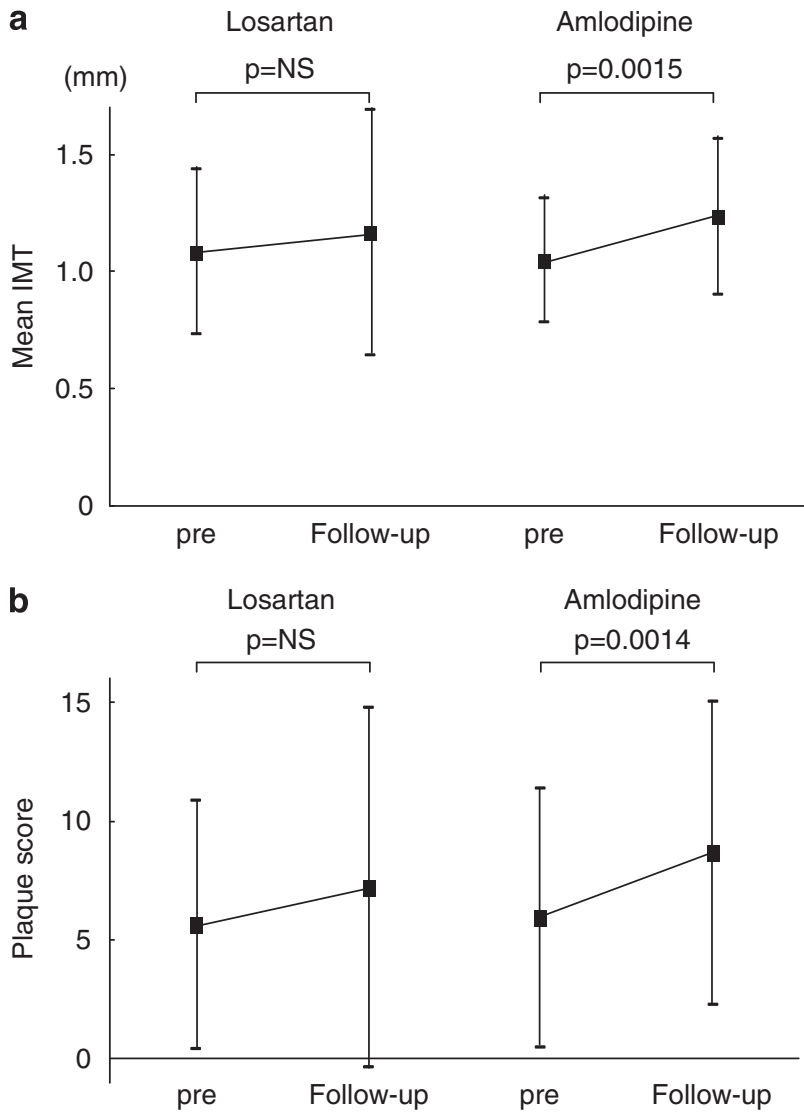

Figure 3 Changes in mean carotid intima-media thickness (mean IMT) (a) and plaque score (b) in each treatment regimen.

amlodipine: $0.6 \pm 0.1 \mathrm{U} \mathrm{ml}^{-1}$ ), telopeptide of collagen type I (losartan: $3.8 \pm 2.2 \mu \mathrm{gl}^{-1}$, amlodipine: $3.2 \pm 1.0 \mu \mathrm{gl}^{-1}$ ), hs-CRP (losartan: $1329 \pm 2048 \mathrm{mg} \mathrm{dl}^{-1}$, amlodipine: $4775 \pm 15583 \mathrm{mg} \mathrm{dl}^{-1}$ ) and creatinine (losartan: $0.9 \pm 0.3 \mathrm{mg} \mathrm{dl}^{-1}$, amlodipine: $0.8 \pm 0.2 \mathrm{mg} \mathrm{dl}^{-1}$ ) at follow-up were not significantly different from those before the initiation of the treatment regimen in either group. Uric acid was significantly decreased by both regimens (losartan: $6.0 \pm 1.6 \mathrm{mg} \mathrm{dl}^{-1}$, amlodipine: $6.2 \pm 1.4 \mathrm{mg} \mathrm{dl}^{-1}$, at follow-up), and there was no difference in the percent changes between the groups (losartan: $-10.5 \pm 16.9 \%$, amlodipine: $-14.3 \pm 18.2 \%)$.

\section{DISCUSSION}

\section{Effects on LV diastolic function}

The J-ELAN study demonstrated that the losartan-based regimen, not the amlodipine-based regimen, significantly shortened DT with the similar blood pressure reduction in patients with mild-to-moderate hypertension and diastolic dysfunction. The shortening of DT can be attributed to the improvement of diastolic function or the elevation of LV filling pressure due to the worsening of diastolic dysfunction. In the losartan-regimen group, there was no change in left atrial dimension, E/A, IRT and BNP, indicating that LV filling pressure was not increased. ${ }^{23,24}$ These data suggest that losartan improves LV diastolic function, although there was no significant change in the other indices for diastolic function, that is, E/A, IRT and BNP. However, DT tended to decrease in the amlodipine-based regimen, and the percent decrease in DT was not different between the two treatment regimens. Thus, this study may not be allowed to make a conclusive remark about the superiority of losartan to amlodipine in the effects on LV diastolic function in Japanese hypertensive patients. The Valsartan in Diastolic Dysfunction trial demonstrated that lowering blood pressure improves diastolic function irrespective of the type of anti-hypertensive agent used. ${ }^{25}$ Diastolic function was assessed with early diastolic mitral annular velocity recorded with tissue Doppler imaging, a sensitive non-invasive index for LV relaxation, in the Valsartan in Diastolic Dysfunction trial. If we had assessed this sensitive tissue Doppler index, we might have been able to obtain convincing results in comparing the effects of $\mathrm{ARB}$ and $\mathrm{CCB}$ on $\mathrm{LV}$ diastolic function.

\section{Effects on LV geometry}

The amlodipine-based regimen, not the losartan-based regimen, significantly reduced LV mass index (Figure 2). However, the percent changes in LV mass index were not different between the groups. There was no significant alteration of BNP during the follow-up period in either regimen. The current results suggest that the amlodipine-based anti-hypertensive therapy attenuates LV hypertrophy; however, the superiority of either treatment regimen to the other in the effects on LV geometry remains unclear.

The lack of changes in amino-terminal propeptide of type III collagen and carboxy-terminal telopeptide of collagen type I suggests that neither treatment regimen changed LV fibrosis. Although experimental studies have shown that ARB prevented the progression of LV fibrosis independent of its anti-hypertensive effects, ${ }^{26,27}$ Diez et al. ${ }^{28}$ showed that treatment with losartan decreased the collagen volume fraction of the ventricular wall in hypertensive patients with severe ventricular fibrosis, but not in patients without severe fibrosis. The subjects of this study had mild-to-moderate hypertension, and only one patient presented symptoms of heart failure. Thus, LV fibrosis of the study subjects may not be severe, reflecting the lack of changes in amino-terminal propeptide of type III collagen and carboxy-terminal telopeptide of collagen type I.

\section{Effects on atherosclerosis of the carotid artery}

The amlodipine-based regimen, not the losartan-based regimen, significantly increased mean IMT and plaque score (Figure 3), and the percent increase in mean IMT tended to be greater in amlodipinebased regimen than in the losartan-based regimen $(P=0.06)$. It is well known that inflammation has an important role in atherosclerosis, and previous studies reported that high hs-CRP value is an independent predictor of carotid atherosclerosis progression. ${ }^{29}$ However, hs-CRP did not significantly change in either regimen group, and there was no correlation between the changes in mean IMT and hs-CRP value in the losartan-based regimen group $(r=0.04)$. Previous studies have shown that an increase in uric acid is associated with progression of atherosclerosis, because its concentration reflects oxidative stress and endothelial dysfunctions. ${ }^{30}$ However, both treatment regimens similarly reduced serum uric acid concentration, and there was no correlation between the changes in mean IMT and uric acid in the losartan-based regimen group $(r=0.07)$. Therefore, losartan may attenuate the progression of atherosclerosis through other mechanisms.

In the previous studies of the Western countries, the administration of amlodipine o $^{31,32}$ or losartan 33,34 decreased IMT. In this study with Japanese patients, amlodipine significantly increased IMT and losartan did not change it, although both decreased blood pressure. The Effects of Amlodipine and Lisinopril on Left Ventricular Mass and Diastolic Function (E/A Ratio) (ELVERA) trial showed the biphasic change in IMT following the amlodipine administration, an increase in IMT at 2 years following the decrease at 1 year of the treatment. ${ }^{32}$ However, the IMT of the amlodipine group was not decreased even at 12 months in 
this study $(1.16 \pm 0.33 \mathrm{~mm})$. The reasons for the less-protective effects of either treatment regimen on IMT in this study compared with the previous studies of the Western countries remain to be clarified. Although blood pressure was significantly reduced in this study, the ideal target blood pressure of the Japanese may be further low to induce the regression of atherosclerotic changes of carotid artery.

Nakamura et al. ${ }^{35}$ recently showed that telmisartan was superior to amlodipine in protecting the worsening of IMT in Japanese hypertensive patients with moderate renal insufficiency, which is partly compatible with our results. In contrast, Ikeda et al. ${ }^{36}$ reported that amlodipine, not ARBs (any of the four agents was used in 46 patients), has an inhibitory effect on early atherosclerotic process of the carotid artery in Japanese hypertensive patients with type 2 diabetes. The Candesartan Antihypertensive Survival Evaluation in Japan (CASE-J) trial showed that candesartan- and amlodipine-based regimens produced no statistical differences in terms of the cerebrovascular events of high-risk Japanese hypertensive patients, but there was a significant difference in blood pressure between the two arms. ${ }^{37}$ Hypertension is a major risk factor for cerebrovascular events, and further clinical studies are necessary to establish appropriate therapeutic regimens for the inhibition of atherosclerotic changes of the carotid artery in Japanese hypertensive patients.

\section{Limitations}

This study has several limitations. First, it was speculated that at least 240 patients were necessary to address the primary aim of this study, to compare the effects of $\mathrm{ARB}$ and $\mathrm{CCB}$ on $\mathrm{LV}$ diastolic function; however, only 57 patients were enrolled. Second, the observational period of this study was only 18 months with the small number of study subjects and the assessment of the effects on surrogate markers. Pharmacological anti-hypertensive interventions within 1 year clarified the significant difference in effects on surrogate markers observed in previous clinical studies. ${ }^{38-40}$ If the number of study subjects was much more in this study, we might have observed a clear difference in the effects on markers between the two regimens. However, the desirable endpoints of clinical trials are cardiovascular and cerebrovascular events and death, and hence future clinical studies with more patients and longer observational period are required. Third, electrocardiographic changes were not assessed in this study, and the comparison with previous studies was not allowed in this standpoint.

\section{CONCLUSIONS}

Under the similar reduction of blood pressure, losartan is likely effective in protecting the progression of atherosclerosis of the carotid artery compared with amlodipine in Japanese patients with mild-tomoderate hypertension, LV hypertrophy, diastolic dysfunction and preserved systolic function, and its benefits may be provided through mechanisms other than anti-inflammatory effects. Losartan may improve LV diastolic function, and amlodipine may attenuate LV hypertrophy; however, this study cannot make consecutive remarks about the superiority of either treatment regimen in the effects on cardiac function and geometry.

\section{ACKNOWLEDGEMENTS}

This study is supported by grants and endowments from Banyu Pharmaceutical through the Osaka Heart Club. We gratefully acknowledge the support by Ms Ayako Fukuda, Ms Sonoko Ishizuka, Ms Keiko Ono and Ms Tomoko Suzuki (Japan Clinical Research Assist Center (JCRAC), Tokyo, Japan) in data management, Ms Masami Yoshioka and Ms Keiko Mizokami (Advanced Harmonic Information Technology, Osaka, Japan) in data collection, and Ms Marie Kusaka (Osaka University Graduate School of Medicine, Osaka, Japan) in secretarial assistance.
1 Chobanian AV, Bakris GL, Black HR, Cushman WC, Green LA, Izzo Jr JL, Jones DW, Materson BJ, Oparil S, Wright Jr JT, Roccella EJ. The seventh report of the Joint Committee on prevention, detection, evaluation, and treatment of high blood pressure. JAMA 2003; 289: 2560-2572.

2 Julius S, Alderman MH, Beevers G, Dahlof B, Devereaux RB, Douglas JG, Edelman JM, Harris KE, Kjeldsen SE, Nesbitt S, Randall OS, Wright Jr JT. Cardiovascular risk reduction in hypertensive black patients with left ventricular hypertrophy: the LIFE study. J Am Coll Cardiol 2004; 43: 1047-1055.

3 Wright JT, Dunn JK, Cutler JA, Davis BR, Cushman WC, Ford CE, Haywood LJ, Leenen $\mathrm{FH}$, Margolis KL, Papademetriou V, Probstfield JL, Whelton PK, Habib GB. Outcomes in hypertensive black and nonblack patients treated with chlorthalidone, amlodipine, and lisinopril. JAMA 2005; 293: 1595-1608.

4 Aurigemma GP, Gottdiener JS, Shemanski L, Gardin J, Kitzman D. Predictive value of systolic and diastolic function for incident congestive heart failure in the elderly: the Cardiovascular Health Study. J Am Coll Cardiol 2001; 37: 1042-1048.

5 Bella JN, Palmieri V, Roman MJ, Liu JE, Welty TK, Lee ET, Fabsitz RR, Howard BV, Devereux RB. Mitral ratio of peak early to late diastolic filling velocity as a predictor of mortality in middle-aged and elderly adults: the Strong Heart Study. Circulation 2002; 105: 1928-1933.

6 Tsuchihashi-Makaya M, Hamaguchi S, Kinugawa S, Yokota T, Goto D, Yokoshiki H, Kato N, Takeshita A, Tsutsui H. Characteristics and outcomes of hospitalized patients with heart failure and reduced vs preserved ejection fraction -a report from the Japanese Cardiac Registry of Heart Failure in Cardiology (JCARE-CARD). Circ J 2009; 73: 1893-1900.

7 O'Leary DH, Polak JF, Kronmal RA, Manolio TA, Burke GL, Wolfson Jr SK. Carotid-artery intima and media thickness as a risk factor for myocardial infarction and stroke in older adults. N Engl J Med 1999; 340: 14-22.

8 Lorenz MW, von Kegler S, Steinmetz H, Markus HS, Sitzer M. Carotid intimamedia thickness indicates a higher vascular risk across a wide age range. Prospective data from Carotid Atherosclerosis Progression Study (CAPS). Stroke 2006; 37: 87-92.

9 Fernandes VR, Polak JF, Cheng S, Rosen BD, Carvalho B, Nasir K, McClelland R, Hundley G, Pearson G, O'Leary DH, Bluemke DA, Lima JA. Arterial stiffness is associated with regional ventricular systolic and diastolic dysfunction: the Multi-Ethnic Study of Atherosclerosis. Arterioscler Thromb Vasc Biol 2008; 28: 194-201.

10 Nishikawa N, Masuyama T, Yamamoto K, Sakata Y, Mano T, Miwa T, Sugawara M, Hori M. Long-term administration of amlodipine prevents decompensation to diastolic heart failure in hypertensive rats. J Am Coll Cardiol 2001; 38: 1539-1545.

11 Sakata Y, Masuyama T, Yamamoto K, Doi R, Mano T, Kuzuya T, Miwa T, Takeda H, Hori $M$. Renin angiotensin system-dependent hypertrophy as a contributor to heart failure in hypertensive rats: different characteristics from renin angiotensin system-independent hypertrophy. J Am Coll Cardiol 2001; 37: 293-299.

12 Sakata Y, Yamamoto K, Mano T, Nishikawa N, Yoshida J, Nakayama H, Otsu K, Suzuki K, Tada T, Hori M, Miwa T, Masuyama T. Angiotensin II type 1 receptor blockade prevents diastolic heart failure through modulation of $\mathrm{Ca}^{2+}$ regulatory proteins and extracellular matrix. J Hypertens 2003; 21: 1737-1745.

13 The J-ELAN Investigators. The effect of losartan and amlodipine on left ventricular diastolic function in patients with mild-to-moderate hypertension (J-ELAN): rationale and design. Circ J 2006; 70: 124-128.

14 Dahlof B, Zanchetti A, Diez J, Nicholls MG, Yu CM, Barrios V, Aurup P, Smith RD, Johansson M. Effects of losartan and atenolol on left ventricular mass and neurohormonal profile in patients with essential hypertension and left ventricular hypertrophy. J Hypertens 2002; 20: 1855-1864.

15 Zile MR, Gaasch WH, Carroll JD, Feldman MD, Aurigemma GP, Schaer GL, Ghali JK, Liebson PR. Heart failure with a normal ejection fraction: is measurement of diastolic function necessary to make the diagnosis of diastolic heart failure? Circulation 2001; 104: 779-782.

16 Yamaguchi H, Yoshida J, Yamamoto K, Sakata Y, Mano T, Akehi N, Hori M, Lim YJ, Mishima M, Masuyama T. Elevation of plasma brain natriuretic peptide is a hallmark of diastolic heart failure independent of ventricular hypertrophy. J Am Coll Cardiol 2004; 43: 55-60.

17 Nishio M, Sakata Y, Mano T, Ohtani T, Takeda Y, Hori M, Yamamoto K. Difference of clinical characteristics between hypertensive patients with and without diastolic heart failure: role of diastolic dysfunction and renal insufficiency. Hypertens Res 2008; 31 : 1865-1872.

18 Quinones MA, Waggoner AD, Reduto LA, Nelson JG, Young JB, Winters Jr WL, Ribeiro LG, Miller RR. A new simplified and accurate method for determining ejection fraction with two-dimensional echocardiography. Circulation 1981; 64: 744-753.

19 Devereux RB, Alonso DR, Lutas EM, Gottlieb GJ, Campo E, Sachs I, Reichek N. Echocardiographic assessment of left ventricular hypertrophy: comparison to necropsy findings. Am J Cardiol 1986; 57: 450-458.

20 Takeda Y, Sakata Y, Higashimori M, Mano T, Nishio M, Ohtani T, Hori M, Masuyama T, Kaneko M, Yamamoto K. Noninvasive assessment of wall distensibility with the evaluation of diastolic epicardial movement. J Card Fail 2009; 15: 68-77.

21 Yamagami H, Kitagawa K, Hoshi T, Furukado S, Hougaku H, Nagai Y, Hori M. Association of serum IL-18 levels with carotid intima-media thickness. Arterioscler Thromb Vasc Biol 2005; 25: 1458-1462.

22 Kondo K, Kitagawa K, Nagai Y, Yamagami H, Hashimoto H, Hougaku H, Hori M. Association of soluble intercellular adhesion molecule-1 with carotid atherosclerosis progression. Atherosclerosis 2005; 179: 155-160.

23 Yamamoto K, Redfield MM, Nishimura RA. Analysis of left ventricular diastolic function. Heart 1996; 75(Suppl 2): 27-35. 
24 Yamamoto K, Burnett Jr JC, Jougasaki M, Nishimura RA, Bailey KR, Saito Y, Nakao K, Redfield MM. Superiority of brain natriuretic peptide as a hormonal marker of ventricular systolic and diastolic dysfunction and ventricular hypertrophy. Hypertension 1996; 28: 988-994.

25 Solomon SD, Janardhanan R, Verma A, Bourgoun M, Daley WL, Purkayastha D, Lacourcière Y, Hippler SE, Fields H, Naqvi TZ, Mulvagh SL, Arnold JM, Thomas JD, Zile MR, Aurigemma GP. Effect of angiotensin receptor blockade and antihypertensive drugs on diastolic function in patients with hypertension and diastolic dysfunction: a randomised trial. Lancet 2007; 369: 2079-2087.

26 Yamamoto K, Masuyama T, Sakata Y, Mano T, Nishikawa H, Kondo H, Akehi N, Kuzuya T, Miwa T, Hori M. Role of renin-angiotensin and endothelin systems in development of diastolic heart failure in hypertensive hearts. Cardiovasc Res 2000; 47: 274-283.

27 Yamamoto K, Mano T, Yoshida J, Sakata Y, Nishikawa N, Nishio M, Ohtani T, Hori H, Miwa T, Masuyama T. ACE inhibitor and angiotensin II type 1 receptor blocker differently regulate ventricular fibrosis in hypertensive diastolic heart failure. $J$ Hypertens 2005; 23: 393-400.

28 Diez J, Querejeta R, Lopez B, Gonzalez A, Larman M, Martinez Ubago JL. Losartandependent regression of myocardial fibrosis is associated with reduction of left ventricular chamber stiffness in hypertensive patients. Circulation 2002; 105: 2512-2517.

29 Hashimoto H, Kitagawa K, Hougaku H, Shimizu Y, Sakaguchi M, Nagai Y, Iyama S, Yamanishi H, Matsumoto M, Hori M. C-reactive protein is an independent predictor of the rate of increase in early carotid atherosclerosis. Circulation 2001; 104: 63-67.

30 Gagliardi AC, Miname MH, Santos RD. Uric acid: a marker of increased cardiovascular risk. Atherosclerosis 2009; 202: 11-17.

31 Pitt B, Byington RP, Furberg CD, Hunninghake DB, Mancini GB, Miller ME, Riley W. Effect of amlodipine on the progression of atherosclerosis and the occurrence of clinical events. Circulation 2000; 102: 1503-1510.

32 Terpstra WF, May JF, Smit AJ, Graeff PA, Meyboom-de Jong B, Crijns HJ. Effects of amlodipine and lisinopril on intima-media thickness in previously untreated, elderly hypertensive patients (the ELVERA trial). J Hypertens 2004; 22: 1309-1316.
33 Ludwig M, Stapff M, Ribeiro A, Fritschka E, Tholl U, Smith RD, Stumpe KO. Comparison of the effects of losartan and atenolol on common carotid artery intimamedia thickness in patients with hypertension: results of a 2-year, double-blind, randomized, controlled study. Clin Ther 2002; 24: 1175-1193.

34 Olsen MH, Wachtell K, Neland K, Bella JN, Rokkedal J, Dige-Petersen H, Ibsen H. Losartan but not atenolol reduce carotid artery hypertrophy in essential hypertension. A LIFE substudy. Blood Press 2005; 14: 177-183.

35 Nakamura T, Inoue T, Suzuki T, Kawagoe Y, Ueda Y, Koide H, Node K. Comparison of renal and vascular protective effects between telmisartan and amlodipine in hypertensive patients with chronic kidney disease with mild renal insufficiency. Hypertens Res 2008; 31: 841-850.

36 Ikeda H, Minamikawa J, Nakamura Y, Honjo S, Hamamoto Y, Wada Y, Nabe K, Koshiyama $\mathrm{H}$. Comparison of effects of amlodipine and angiotensin receptor blockers on the intima-media thickness of carotid arterial wall (AAA study: amlodipine vs ARB in atherosclerosis study). Diabetes Res Clin Pract 2009; 83: 50-53.

37 Ogihara T, Nakao K, Fukui T, Fukiyama K, Ueshima K, Oba K, Sato T, Saruta T. Effects of candesartan compared with amlodipine in hypertensive patients with high cardiovascular risks: candesartan antihypertensive survival evaluation in Japan trial. Hypertension 2008; 51: 393-398.

38 Lopez B, Querejeta R, Varo N, Gonzalez A, Larman M, Martinez Ubago JL, Diez J. Usefulness of serum carboxy-terminal propeptide of procollagen type I in assessment of the cardioreparative ability of antihypertensive treatment in hypertensive patients. Circulation 2001; 104: 286-291.

39 Ciulla MM, Paliotti R, Esposito A, Diez J, Lopez B, Dahlof B, Nicholls MG, Smith RD, Gilles L, Magrini F, Zanchetti A. Different effects of antihypertensive therapies based on losartan or atenolol on ultrasound and biochemical markers of myocardial fibrosis: Results of a randomized trial. Circulation 2004; 110: 552-557.

40 Devereux RB, Dahlof B, Gerdts E, Boman K, Nieminen MS, Papademetriou V, Rokkedal J, Harris KE, Edelman JM, Wachtell K. Regression of hypertensive left ventricular hypertrophy by losartan compared with atenolol: The losartan intervention for endpoint reduction in hypertension (LIFE) trial. Circulation 2004; 110: 1456-1462. 